\title{
The Cost-Benefit Relations of the Future Environmental Related Developments Strategies in the Hungarian Energy Sector
}

\author{
Csaba Fogarassy ${ }^{1}$ and Attila Kovacs ${ }^{2}$
}

\author{
${ }^{1}$ Climate Change Economics Research Centre, Szent István University, Gödöllő, Hungary \\ fogarassy.csaba@gtk.szie.hu \\ ${ }^{2}$ Department of Operations Management and Logistics, Szent István University, Gödöllő, Hungary \\ kovacs.attila@gtk.szie.hu
}

\begin{abstract}
In the case of economic and social wealth, it is strategically essential to provide reliable energy sources which are available in long-term. Setting an energy network which suits the sustainable criteria might take a long time. Therefore, it is important to make decisions on the energy sector in advance. The Hungarian National Energy strategy elaborated on certain scenarios towards 2030, which describe the possible electricity generation opportunities up to 2020 and 2030. For 2020, there is already an accurate recommendation, but in case of the 2030 targets, there are several ways for innovation. Out of all, the realization of the "Nuclear-Carbon-Green" scenario seems most likely to be implemented. It implies the obvious involvement of nuclear energy potential development in the future strategies. Considering this trend, the present study divides the mentioned strategy into "Nuclear-Carbon" and "Nuclear-Green" scenarios to compare their long-term efficiency by economic means.
\end{abstract}

Keywords: energy strategy, nuclear energy, green energy, cost-benefit analysis, climate policy

\section{INTRODUCTION}

Making sure that safe, reliable energy sources are accessible long-term is a strategic goal which is important from the perspective of social welfare as well [1]. Constructing energy systems also adhering to the criteria of sustainability may take a long time to do, which is why decisions related to future developments concerning energy have to be decided in time.

According to the data of the International Energy Agency, the demand for energy worldwide increased by nearly $120 \%$ between 1971 and 2013. Earth's energy usage increased to almost 13,5 equivalent tonnes by 2015 , almost $81 \%$ of which consists of fossilized energy resources, and the ratio of nuclear energy is around $5 \%$, whereas the share renewable energy resources own amounts to almost nothing [2]. The rising demand for energy, the competition on the world market getting more serious, and present tendencies suggest that the increase in energy usage will continue in the future as well, and the extraction volume of fossilized energy resources won't be sustainable. Alternative solutions will be needed [3].

Based on the data of Eurostat, the consumption of the European Union was somewhere around 1600 million tonnes of oil equivalent in 2013. Compared to the 1990's, similar extreme increases could only be seen in 2005 . At that time, nearly 1800 million equivalent tonnes were registered, but this receded to the 1600's nowadays [4]. The gross energy consumption of the European Union depends on the individual energy demand of its member states, which shows a large variety. It's dependent on the structure of the energy system, the accessibility 
of primary resources, and the structure of the economic system and the development level of said countries. Increasing energy supply via the liberalization of the electric energy and gas markets is important in Europe, in order to aid the expansion of the renewable energy market, and presence of smaller market actors [5].

According to the strategy of Hungary, tailored until 2020, the following perspectives have to be kept in sight during the structure change of energetics [6]:

- Energy efficiency measures influencing the entire supply and consumption chain;

- Increasing the production rate of low $\mathrm{CO}_{2}$ intensity electric energy - mainly from renewable energy resources;

- Advocating renewable and alternative heat production methods;

- Increasing the share low $\mathrm{CO}_{2}$ emission methods have in traffic methods.

By realising these points, we can make a huge leap towards realising sustainable and safe energetic systems, which can also contribute to the intensity of economic competitiveness [7]. The future will probably bring the increase of energy demand worldwide, most notably in developing countries. Satisfying these demands poses a challenge to both the actors of the political and the economic world $[8,9]$.

The National Energy Strategy issued in 2012 details the following priorities to be realised long-term, until 2030, in order to create a sustainable energy production [10]:

1. Increasing energy conservation and energy efficiency;

2. Increasing the ratio of renewable energy resources in consumption;

3. Integrating the Central European cable system, and making the border-crossing capacities required for this;

4. Keeping the current capacity of nuclear energy;

5. Environment-friendly usage of domestic coal- and lignite-resources in electric energy production.

Various different scenarios were detailed in the National Strategy until 2030, which describe the possibilities of electric energy production until 2020 and 2030. There's an actual concept for 2020, and for 2030, the "Atom-Coal-Green" scenario is the most likely to be realised, according to the National Strategy. This also means that nuclear energy is present within the strategies. In case "Paks 2" isn't constructed for some reason, the share nuclear energy has in energy consumption will still be increased via expanding the capacity of block 1 . Based on this scenario, the share renewable energy has in consumption will stay below the 2020 goals, and we can assume it won't even reach $20 \%$ share, though technological solutions would make this possible.

The priority among renewable energy resources is focused on cogeneration biogas and biomass plants, and forms of geothermic energy utilization, which mainly, but not exclusively, produce heat. Also, an increase is assumed to happen in the usage of heat- and electric energy produced from solar energy, and electric energy produced from wind energy. Using the domestic solar energy potential for directly generating electric energy will become possible after 2020, due to the decrease in photo-electric technological solutions' prices. 
From the perspective of bio-energy utilisation, de-centralised energy production units using source materials from energetic plantations, and by-products of agricultural and industrial (f.e. foodstuff industry) activities will gain an advantage. Another important problem that needs a solution is the fate of communal and industrial waste unusable on their own, and wastewater. Apart from the gain of renewable energy resources, the scenario counting on new nuclear power plant block(s) also estimates that by 2030, the share of nuclear energy in consumption will also increase from today's $16 \%$ by 2030 (Figure 1).

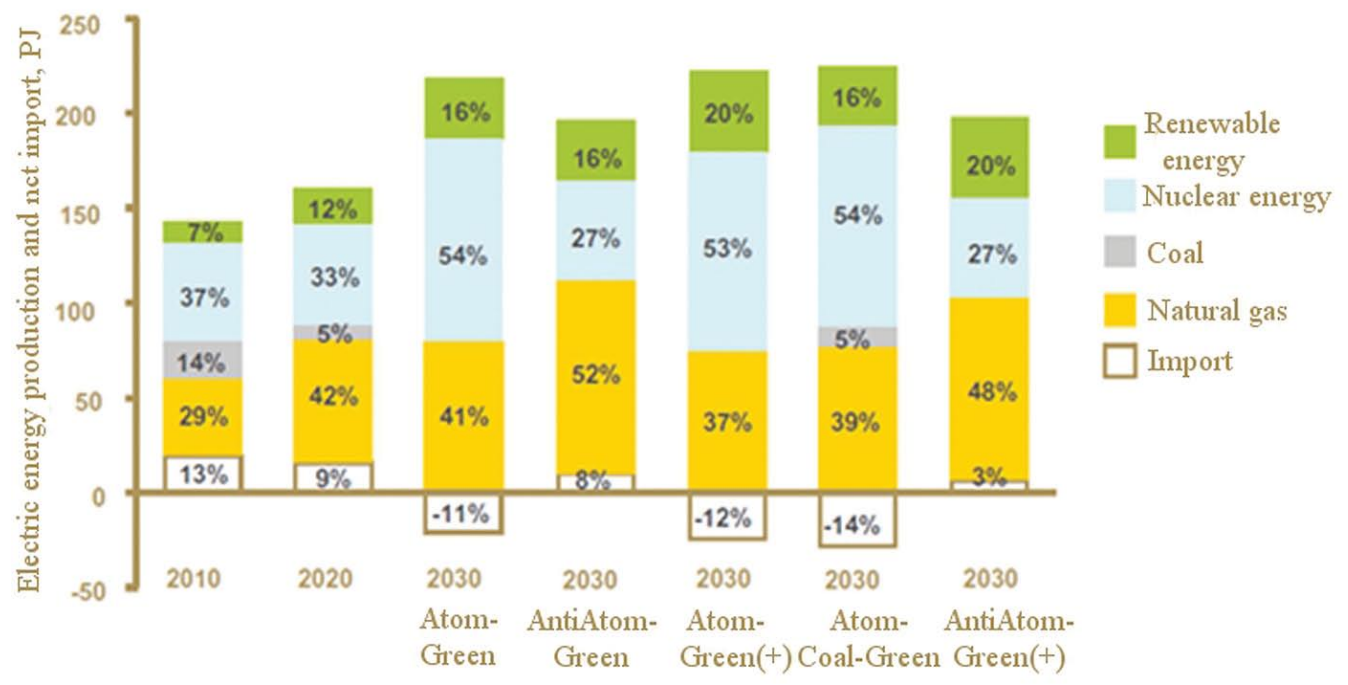

Figure 1. Estimated energy production of Hungary in different energy mixes Source: [10]

This makes the significant decrease of fossilized energy resources' share in consumption possible, and also the decrease of emitting greenhouse gases via energy production [10]. The goal of the study is to evaluate scenarios similar to the strategic plans from an economic perspective, where we allocate either fossilized, or green development processes to plans based on nuclear energy individually.

\section{SOURCE AND METHOD}

\section{Climate policy CBA model designed for the analyses}

Decision making nowadays requires the usage of CBAs (cost-benefit analyses) before investments and development projects. Its goal is to make us capable of defining the project's conclusions in monetary terms [11]. During the development of the methodology, we can see that segments which were either fully, or partially incapable of being assigned a monetary side had less importance during decision-making. Economics call these factors externalities [12], and the most important perspective of making new CBA models is to internalise these externalities - in other words, to define them in monetary terms. During our research, we based on the method defined by the COWI group, commissioned by the European Union. Their process doesn't only aim to realise profit maximisation, the focus of a company's interests, but also accounts for indirect effects from the social and environmental sides, in other words, externalities. Of course, externalities can't be completely defined in monetary terms even with this system, but it's effective in estimating them, using the fiscal corrections. 
This is the basis of the GHG balance changes' clearance, the most important innovation of our own model based on COWI's methodology. We first define a normal business ('business as usual'), which could be actualised if we wouldn't intervene in the sector's inner workings with our project. After this, we added climate policy measures to our next scenario, which was deemed the "Project" version. We measured the GHG effect using the $\mathrm{CO}_{2}$ equivalent used by the European Union [13], while the cash flow realised through it was entered into the balance sheet using the quota price estimates of the EU ETS until 2030. The other important aspect apart from working out the CBA model is how to handle multi-purpose factors [14]. Multiple economic analyses handle these situations as a one-purpose economic situation. Our analysis, however, uses the process where all goals are set during the model's query, and only one of them is changed. Later, we repeat the analysis for the other goals as well, and document the results. The results we get form a solution space, in which we can modify measures as we deem fit, in order to realise a best practice.

The model we introduced is based on the following cost-benefit analysis equation [15]:

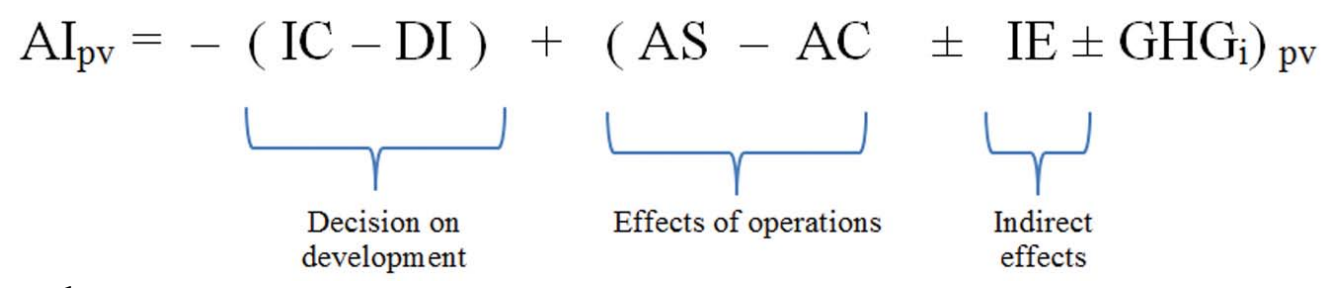

where:
$\mathrm{AI}_{\mathrm{pv}}=$ the present value of additional income
$\mathrm{IC}=$ the additional investment cost of the equipment to be purchased (EUR)
$\mathrm{DI}=$ possible support and discounts (EUR)
$\mathrm{AS}=$ the additional sales revenue resulting from the additional yield or increase in quality attributed to using the given technology (EUR/year)
$\mathrm{AC}=$ the balance of the given technology's additional costs and its possible savings (EUR/year)
$\mathrm{IE}=$ the indirect economic impacts (environmental effects, effects on society)
of using the given technology and the value of GHG reduction (EUR/year)
$\mathrm{GHG}_{\mathrm{i}}=$ the indirect effects on emissions of using the given technology,
based on the value of the decrease in GHGs as per the EU ETS quota
forecast (EUR/year)
$\mathrm{pv}=$ present value

Our own CBA model's innovative element is the "Indirect effects" point of the equation's latter part, where we translate the project's effects that contain climate policy elements to monetary terms. Since the goal of the analysis is to evaluate the projects generating GHG emission decrease from an economic perspective, we cleared the effects of their resulting environmental, economic and social externalities here.

\section{RESULTS}

We theorised two distinct, basic cases during our scenarios: one is when processes are continued according to the current political and subsidy system, called "business as usual" by foreign sources (referred to as BAU). 
Another is when we allocated the sector substantial resources in the form of a project, in order to decrease the carbon-dioxide emission that happens.

\section{Scenario1: Atom expansion and keeping carbon deposits}

General theories

We basically suppose that both household, and non-household categories will increase their consumption (Figure 2). The reason for this is that getting out of the economic slump automatically causes the increase of production and consumption [16].

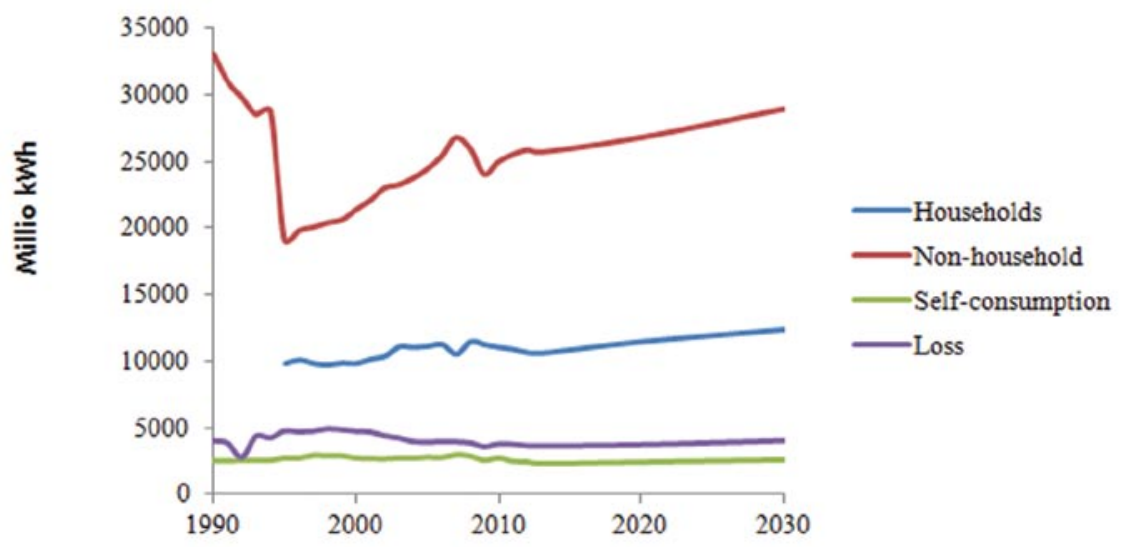

Figure 2. Estimation of consumption

The increase in consumption estimates an average $8 \%$ increase compared to the state of 2020. Compared to the earlier version, the decrease in self-consumption and losses has no reality for the Scenario 1 version, since the operations aren't insular or local, but deal with the distribution into the system, meaning a slight increase can be theorised in this perspective. However, we didn't calculate with this increase.

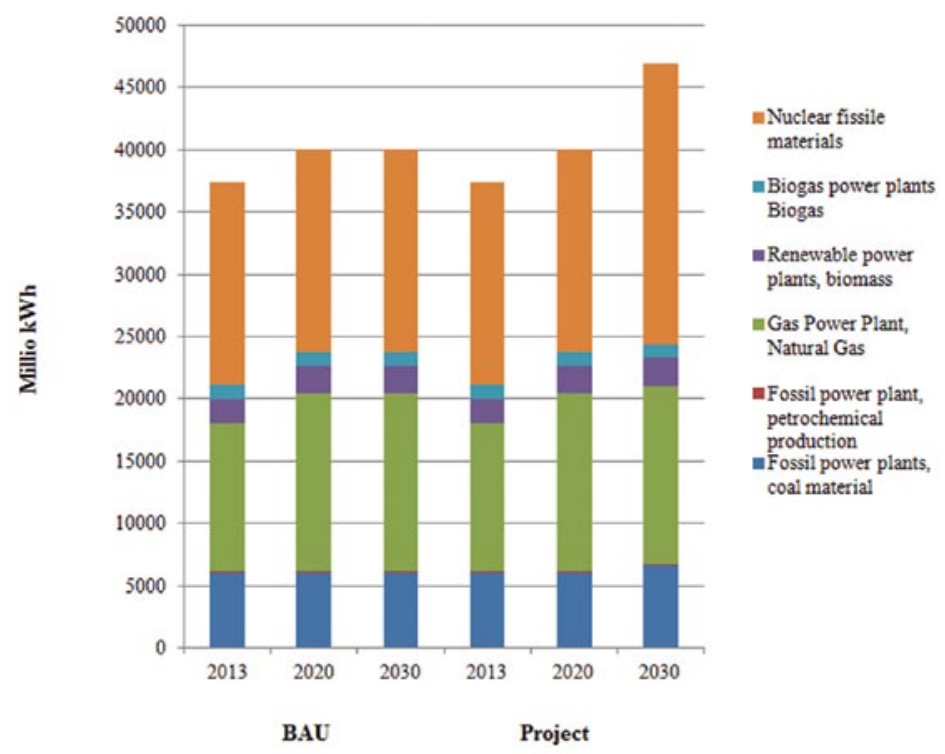

Figure 3. Ratios of domestic electric energy production by type of plant 
We can see how the structure fundamentally changes, due to the increase in share of fossilized plants and nuclear plants (Figure 3). Thanks to the nuclear plant expansion, the project can generally create a kWh of energy at lower cost, but the general economic efficiency can't be realised in this version.

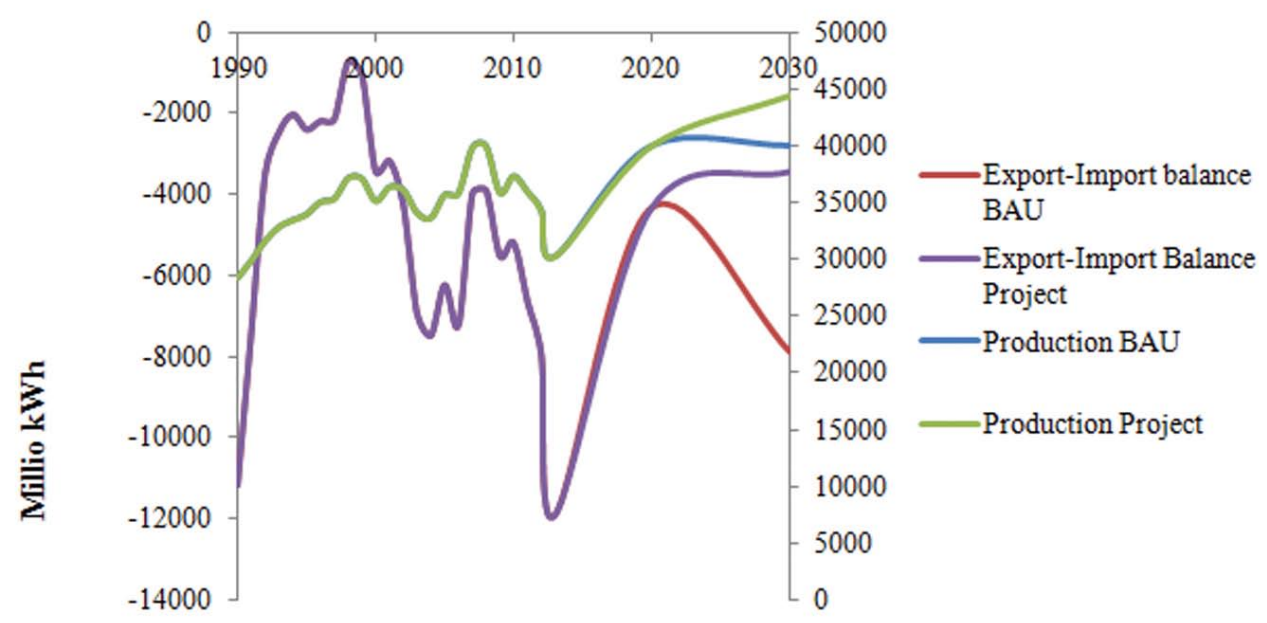

Figure 4. Changes of production, and its effect on the import-export balance

Since the capacity of coal-based plants doesn't get decreased, we can foresee a significant decrease in domestic product for the BAU system, due to the EU ETS quota system. In case this won't come to pass, the system's income generation ability would be damaged significantly, meaning the prices of household and industrial electricity would probably increase (Figure 4). This results in the increase of import's share in BAU. This difference makes the Project version more advantageous, however, even this version can't compensate for the income reducing effect of the quantity produced above the quota system, as we'll see in the following Figures.

Obviously, achieving an emission reduction in this scenario (Scenario 1) is impossible, since we have to go until the highest end of the quota threshold due to the enforced effect of import decrease. Because coal plants have to be operated continuously, not even the nuclear power plant system can achieve the size-effective production state [17], meaning payoff indicators can't turn back after 2040. The combined production of the nuclear power plant and coal plants sometimes leads the service systems above, or below the self-sufficient level. We can question the income generation ability of export production, which is why it's effect on NPV is negative.

It's important to note that there's no share of electric energy production using coal or crude oil for the BAU system by 2030. The state introduced in Scenario 1 can only come to pass, in case there's a separate development program tailored to increase production based on coal or crude oil.

\section{Carbon efficiency indicators of Scenario 1}

The most important carbon efficiency indicator would be the 'all GHG emission quantity changes' seen on Figure 5, since this refers to the level of change in the sector's GHG emission balance. Here, we can see that the project should be discarded according to even the most basic of indicators, since not only does it not cause a decrease in the sector's $\mathrm{CO}_{2}$ balance, but induces an increase in it for the 2020-2030 period. 


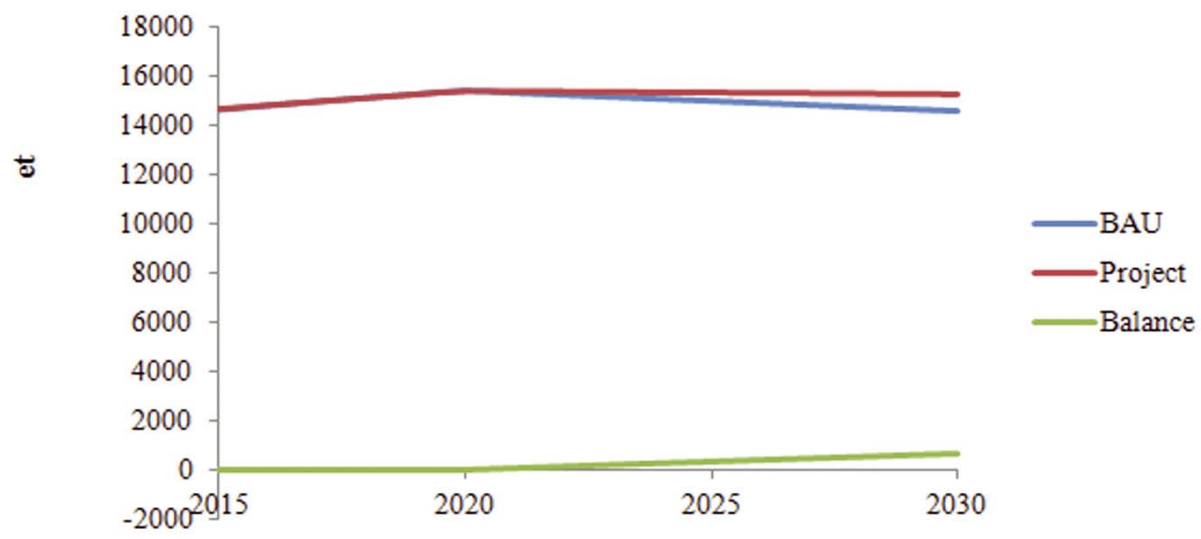

Figure 5. $\mathrm{CO}_{2}$ equivalent change of the sector until 2030

During the actualisation of Scenario 1, both cases cause a decrease in the $\mathrm{CO}_{2}$ emission decrease for each $\mathrm{kWh}$ or produced energy. The latter is seen on Figure 6, where we can see that the $\mathrm{CO}_{2}$ efficiency during the production of only changes minimally from the default system. In this sector, it poses a problem because increasing energy efficiency is also a base indicator used in the European Union's climate policy [18].

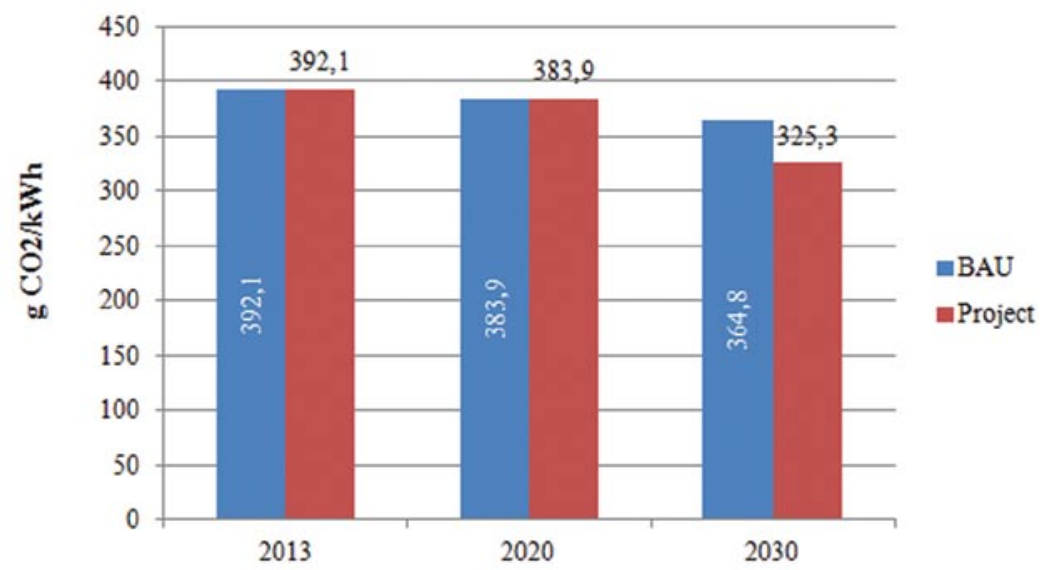

Figure 6. Changes in the average $\mathrm{CO}_{2}$ emission volume per $1 \mathrm{kWh}$ electricity production of the sector until 2030

Finally, Figure 7 shows the changes in low-carbon technological solutions for the sector. These technological solutions mean a lower energy- and material consumption compared to previous practices. In the case of low-carbon solutions, the change of efficiency or increase in performance was defined via the GHG emission avoidance or decrease level. It's an important professional question what kind of energy we consider nuclear energy to be. We categorised it to be a non-renewable energy resource system elements in the Figures, but we have to stress that we handle it as a production process having no GHG emission [19, 20]. All low-carbon technological systems including nuclear power plant production have measurable performance, using the carbon-dioxide equivalent indicator $\left(\mathrm{CO}_{2 \mathrm{e}}\right)$, and describable with the carbon-dioxide (avoidance) efficiency [21]. The share of renewable energy resources in consumption also shows a bad trend in this version, as there are no increases after 2013. 


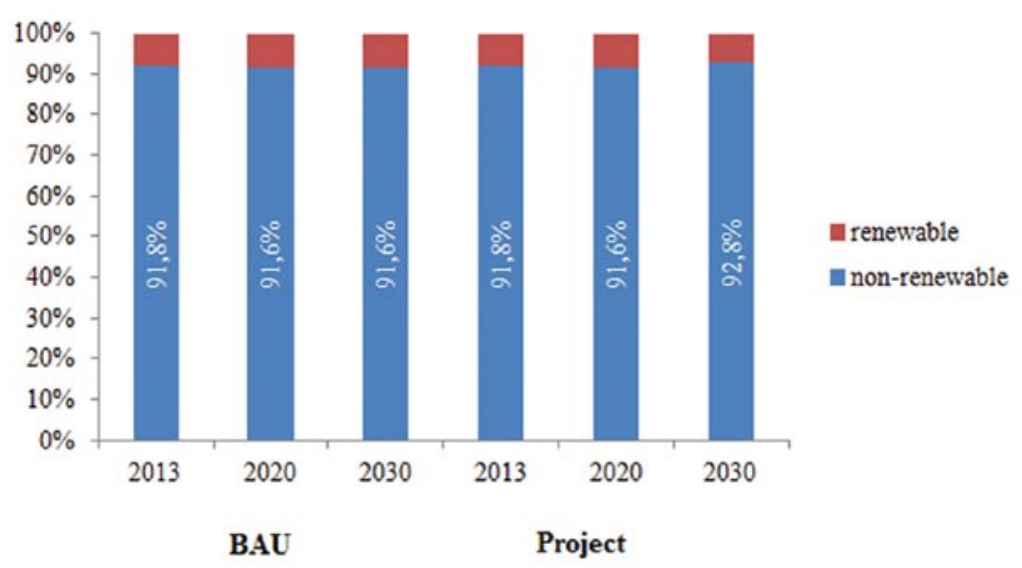

Figure 7. Change of low-carbon technological solutions' share in the sector until 2030

Let's take a look at the economic effects related to the environment side, in other words, indicators describing Scenario 1's payoff.

\section{Financial payoff indicators of Scenario 1}

Figure 8 shows the present value of excess income for the cost-benefit calculation, consisting of both the normal present value (NPV) and the cost-benefit systems of the "business as usual" and project versions compared to each other. We can see in it, that the current state of affairs shows negative tendencies not only on the environment side, but the economic aspects as well, since the investments won't offer a payoff in long-term either.

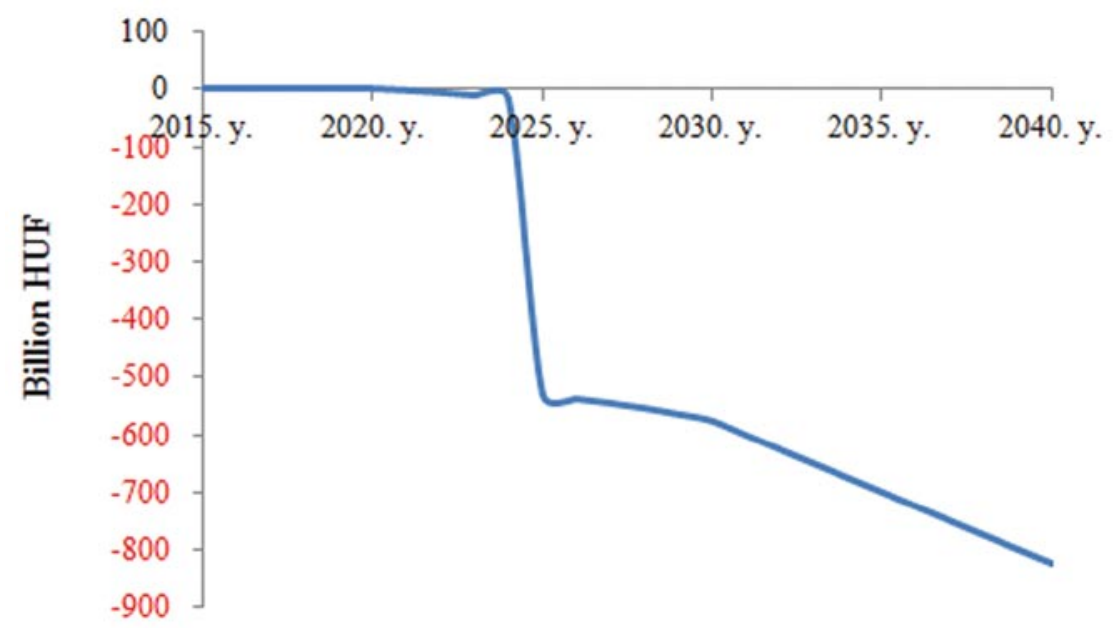

Figure 8. Excess income value of the project's cost-benefit calculation

Figure 9 shows the project variant's payoff probability using the internal payoff rate, and the calculative interest rate. We have to note that all initiatives with a value between $-50 \%$ and $-10 \%$ should be discarded. Investing into the project is only beneficial above $0 \%$, and for the interval of $-10 \%$ and $0 \%$, we could say that the social losses are acceptable. However, according to the deductions from the previous Figure, it's not surprising how the project version's payoff indicators also show negative results. 


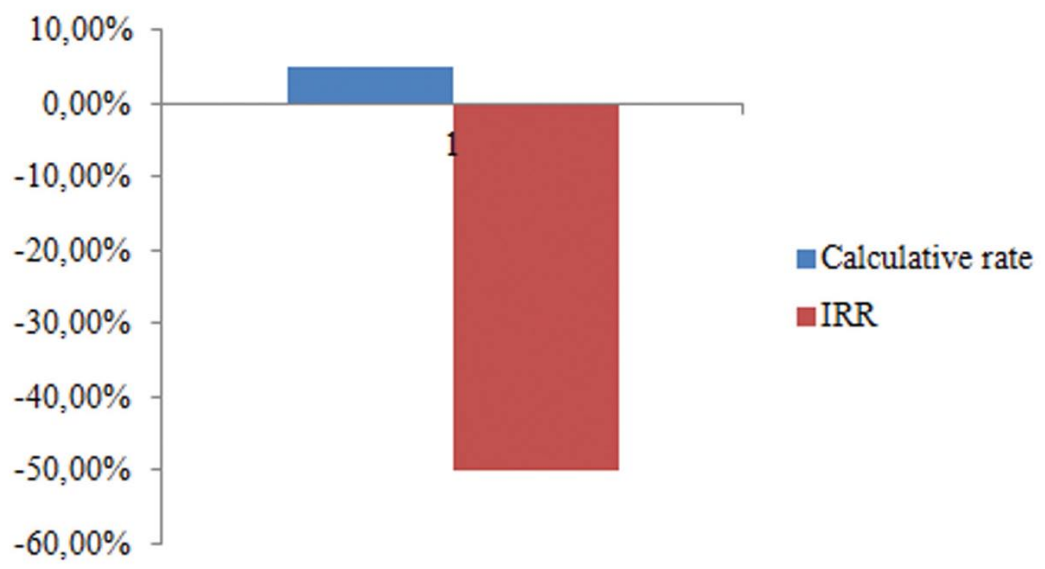

Figure 9. Internal payoff rate of the project

The BCR1 index (Figure 10) shows how the project's generated total payoff relates to the total amount of costs (investing above 1 is generally advantageous, between 0,5 and 1 , we should debate, and investing below 0,5 is generally not advised). The BCR2 index shows how many times our invested capital pays off until 2030. All financial indexes show tendencies suggesting that we discard this variant, even though in certain time frames, the efficiency indicator seems to be more advantageous due to the higher share nuclear energy has compared to BAU. However, we have to stress that we can theorise Scenario 2 to have $\mathrm{a}_{2}$ equivalent emission increase compared to BAU.

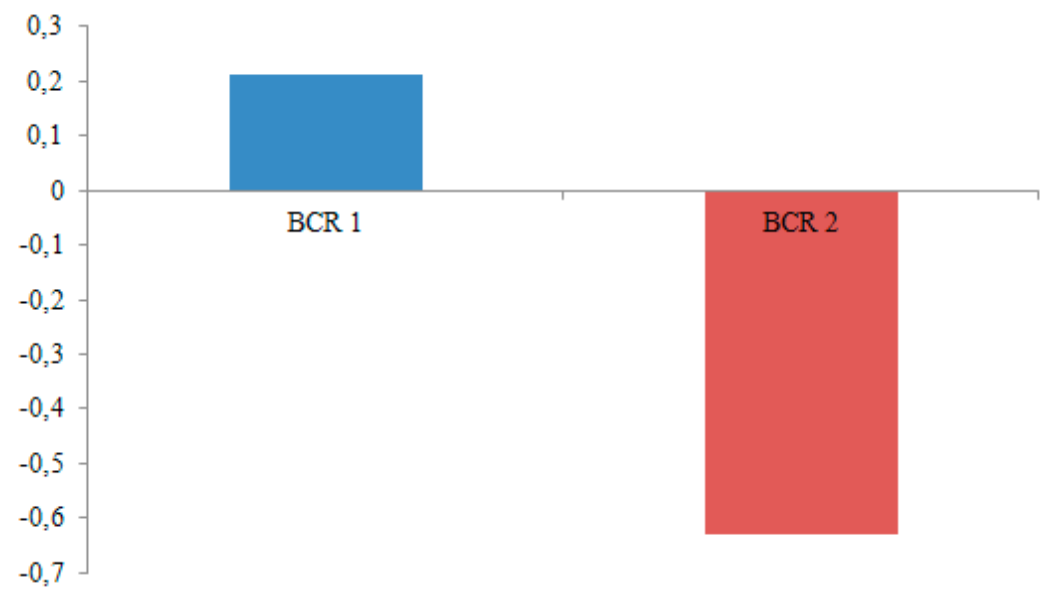

Figure 10. Income-cost indicators of the project

\section{Evaluation of Scenario 1}

Based on the sectors' analysis, we can already say that the current project - standing really close to actual development ideas - can be considered to be the worst among variants, seeing nothing more than previous Figures. This is due to the payoff tendency of investments being left behind, not to mention we can't reach our goals either, meaning there's no decrease in GHG emission rates. Therefore, it's no surprise that the scenario's in the upper left corner of carbon orientation matrix (Figure 11), based on the summarised emission indicators. This is why actualising the project in its current state is not advised. 


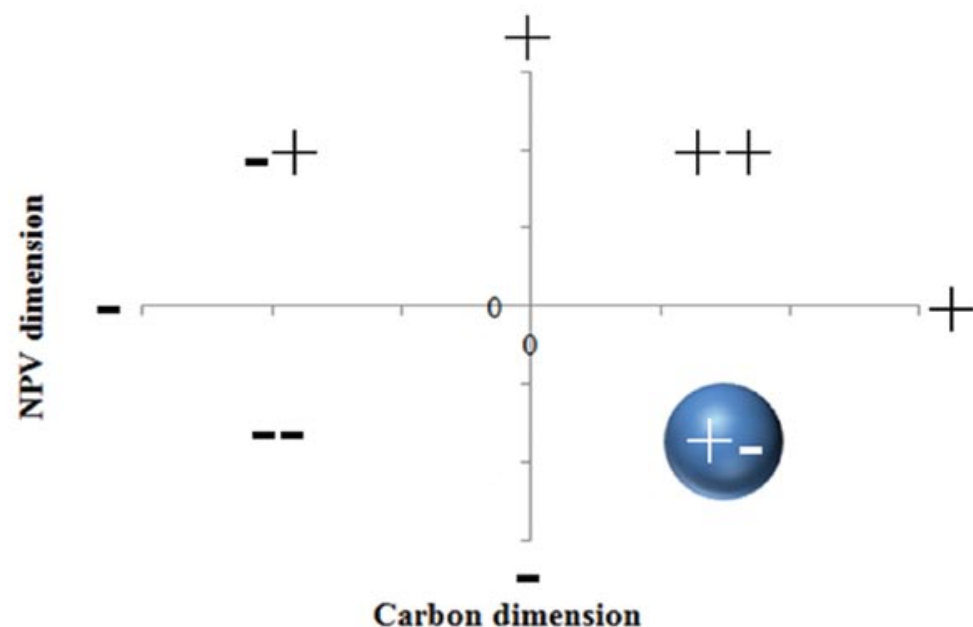

Explanation:

Figure 11. Carbon orientation matrix of Scenario 1

-+ : The case when we actualise a project that only increases our emission, and our investment never pays off.

++ : The case when the project may show out invested costs to have payoff tendencies, but the activity itself wasn't appropriate to decrease GHG emission.

- - : The case when only high - and non-payoff - costs are required to decrease emission rates.

+- : Acceptable scenarios, which we can use to generate a $\mathrm{CO}_{2}$ equivalent emission decrease if we allow our investments to pay off in a while. (Even investments paying off after their life cycle, which may have changing externality contents based on political preferences.)

\section{Scenario 2: Atom+Green investment, self-consumption and losses improved}

General assumptions

We make the general assumption that both household, and non-household categories increase their consumption. We do this because after the economic slump, both production and consumption automatically increase.

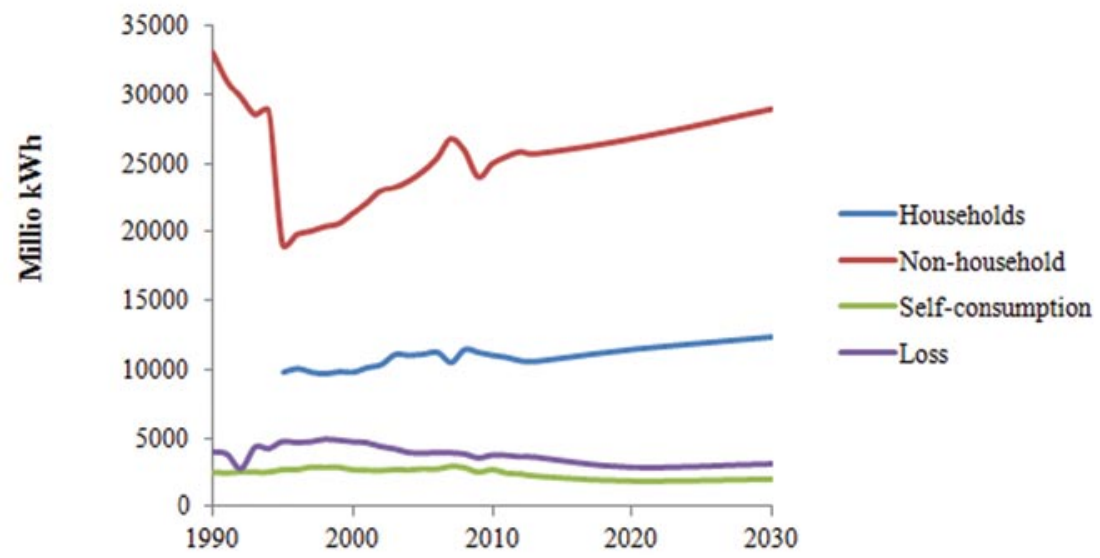

Figure 12. Estimated consumption with prognosis 
The growth assumes an $8 \%$ change compared to the 2020 state. The change in structure is shown by the Figure 12 above. Scenario 2 counts on the planned nuclear power plant block expansion to be accompanied by a continuous increase of green investments, a decrease of the system's self-consumption, and a significant decrease in losses, since a significant decentralisation in production can be theorised due to the system of green energy production. In this variant, electric energy production using coal and crude oil isn't present for the 2030 goal value. The "domestic electric energy production by plant type" Figure shows how fossilized heat plants' energy production completely disappears from the portfolio, and that the renewable energy plant capacity, and biogas-based electric energy production increases to twice its value in BAU.

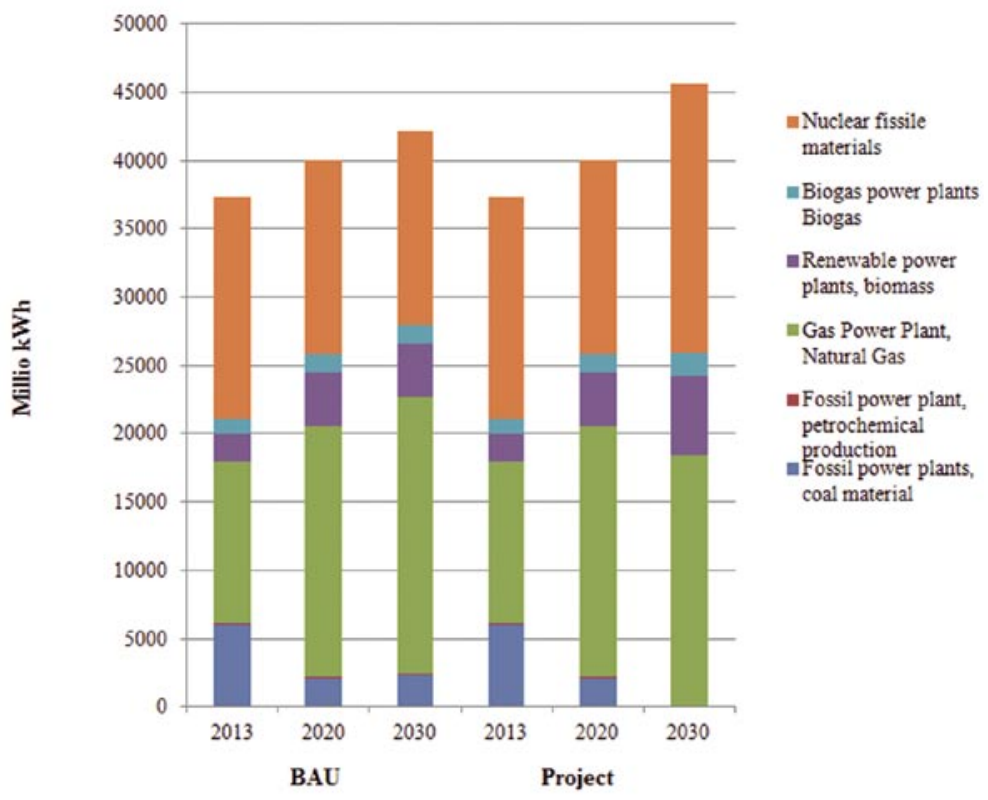

Figure 13. Domestic electric energy production by plant type

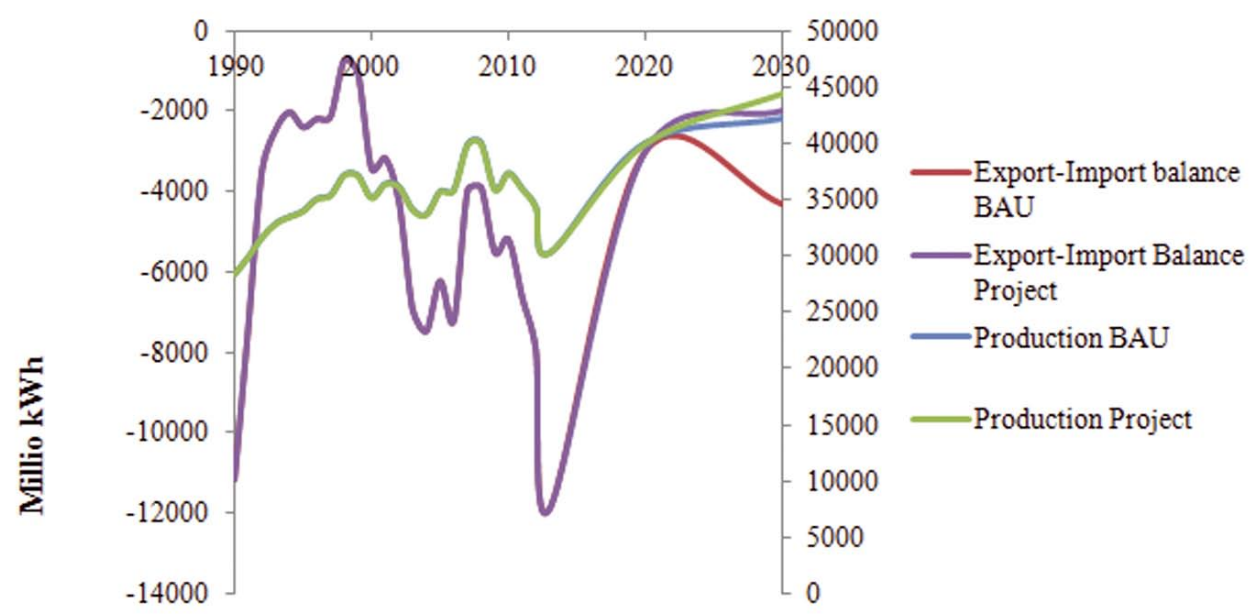

Figure 14. Export - import balance 
The Figures 13 and 14 above shows that the sector can realise product marketing increase due to the project's effect without having to buy excess quota, compared to BAU. This also has an advantageous effect on the export-import balance. The sector is basically import-oriented, which is defined by the left scale. We can see on it that due to the project's effect, the quantity of import decreases compared to BAU, and how much the decrease amounts to.

\section{Carbon efficiency indicators of Scenario 2}

Similarly to the previous scenario, Figures 15,16 and 17 show us how the indicators influencing Scenario 2's GHG emission balance changed. The reason for $\mathrm{CO}_{2}$ efficiency is the change in the structure, as the share low-carbon technologies in used technological solutions increase. The change in structure is shown on Figure 17. We can follow the efficiency of $\mathrm{CO}_{2}$ emission by production unit after 2020 . We can clearly see how $100 \mathrm{gs}$ of savings can be realised on average due to the effects of the production structure changes. If we look at the tempo green technological solutions increase, we can see how their share in production structure increases above $15 \%$, compared to BAU's $12 \%$. This directly causes the sector's $\mathrm{CO}_{2}$ equivalent balance to show more than -3000 kilo-tonnes of savings (Figure 15).

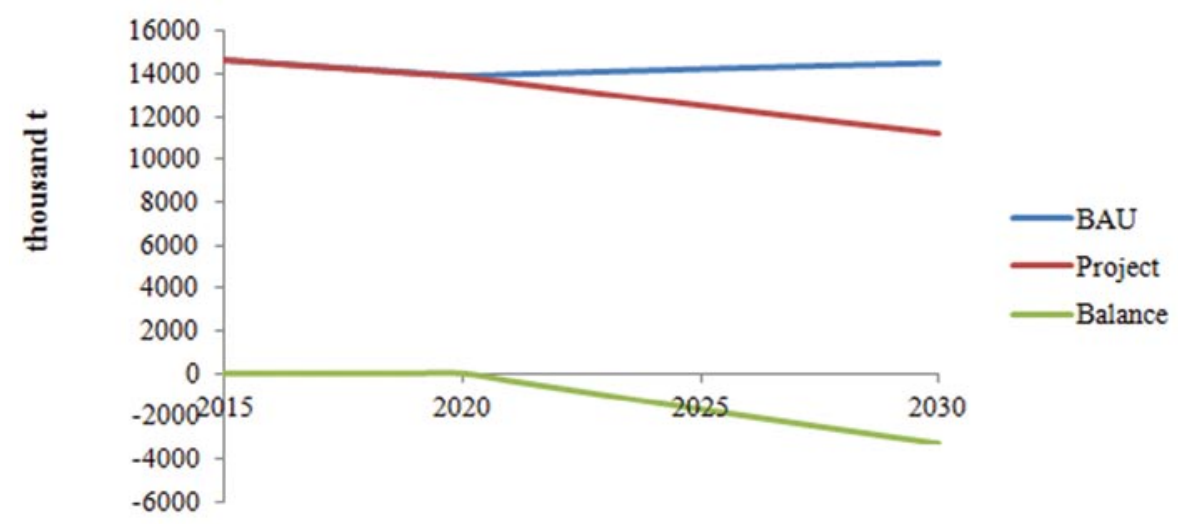

Figure 15. The sector's $\mathrm{CO}_{2}$ equivalent changes until 2030

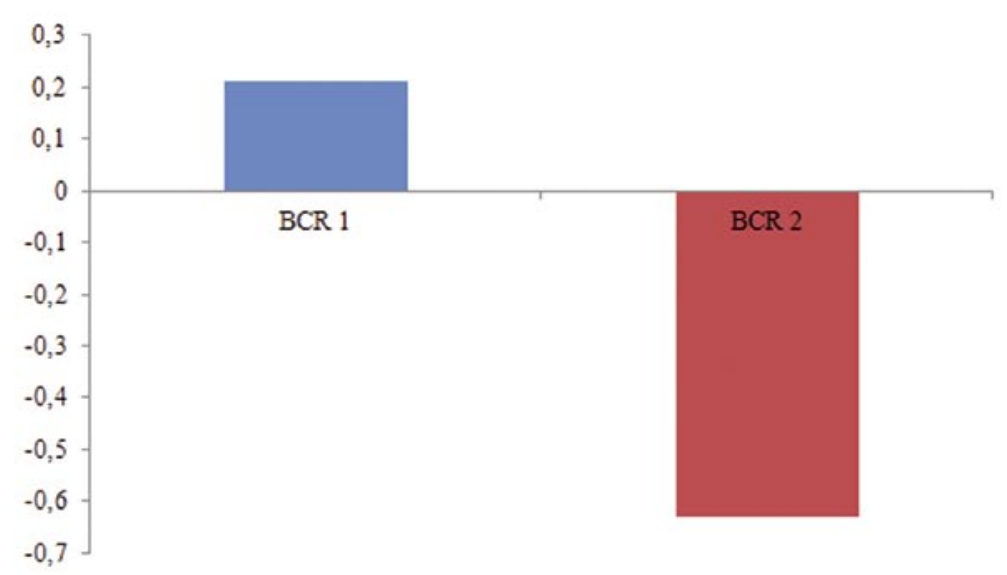

Figure 16. Changes in the average $\mathrm{CO}_{2}$ equivalent efficiency of the sector until 2030 


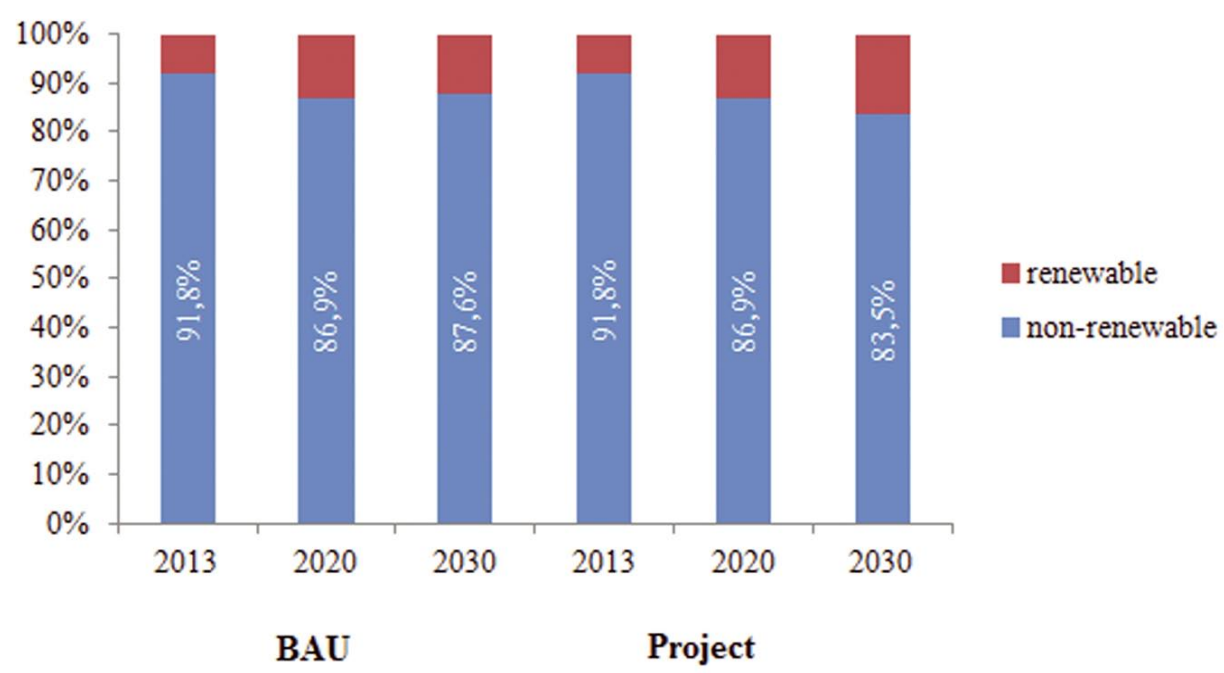

Figure 17. Change of low-carbon technological solutions' share in the sector until 2030 And now, let's take a look at the economic indicators of Scenario 2.

\section{Scenario 2's financial payoff indicators}

Based on comparing BAU and the project according to the base equation, the results of differences between the two, related to the financial perspective can be seen on Figures 18, 19 and 20. If we look at the net present value diagram, we can see that the green technologies installed during the first step cause the NPV to increase, meaning payoff is guaranteed. The investment also shifts into an increasing tendency on its own during a long-term analysis, and after the Atom expansion goes into effect one again, but from a lower starting rate understandably, due to the investment. This supports the value of internal payoff rate being close to the calculative interest rate, meaning the analyses' extension until 2050 would show that this investment would also pay off in 25 years.

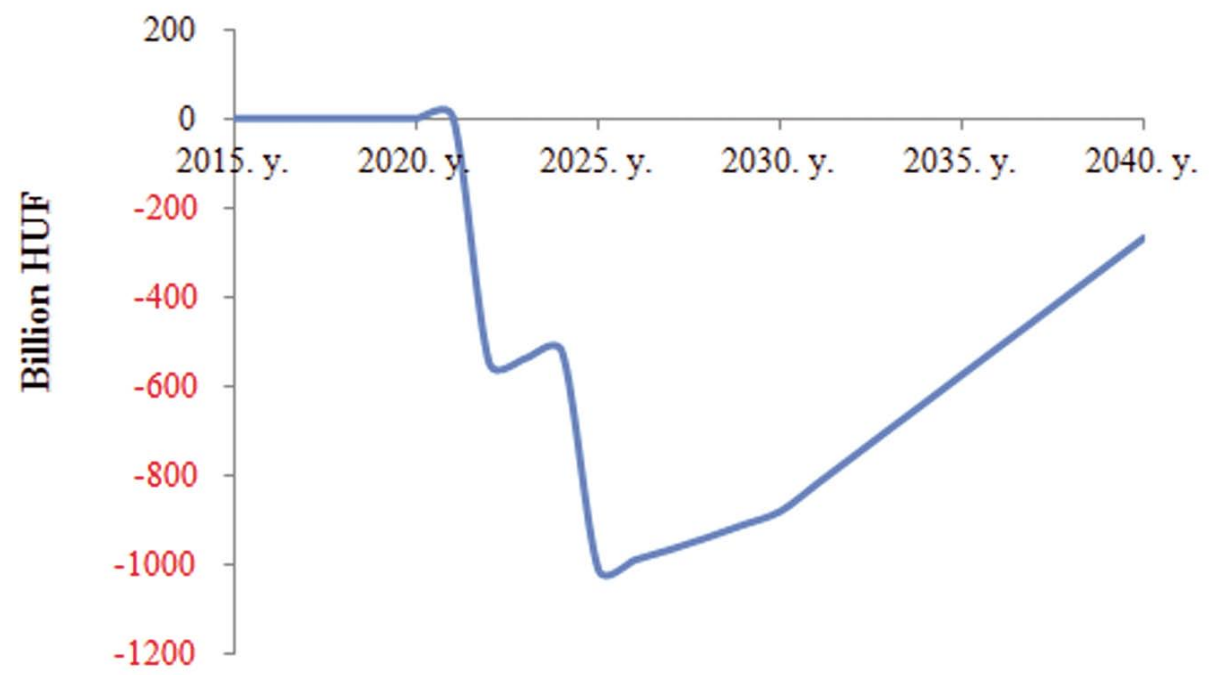

Figure 18. Excess income value of the project's cost-benefit calculation 


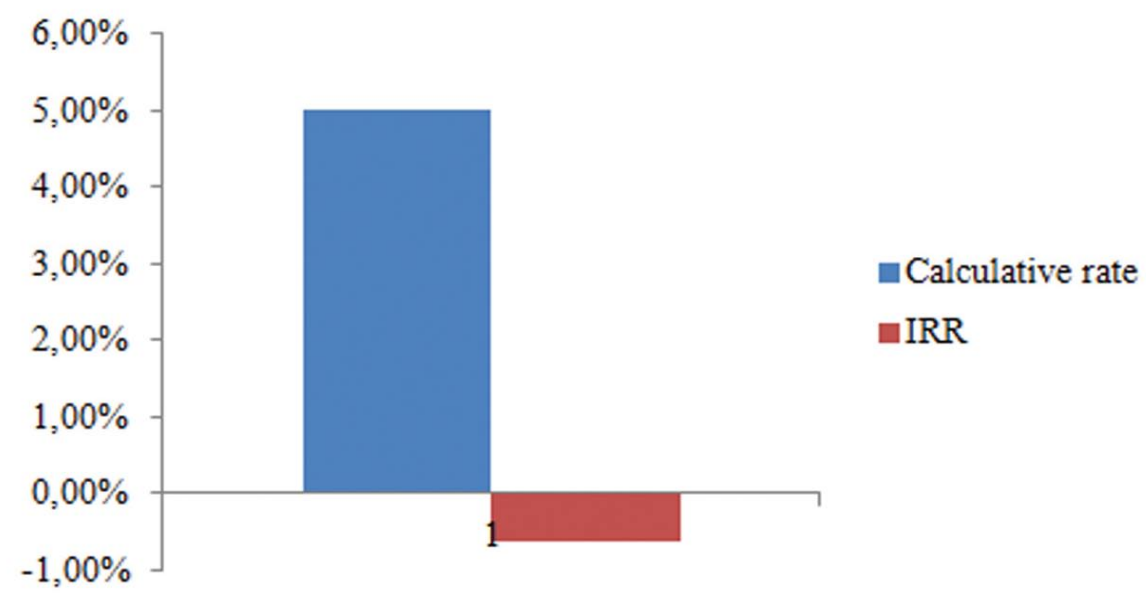

Figure 19. Internal payoff rate of the project

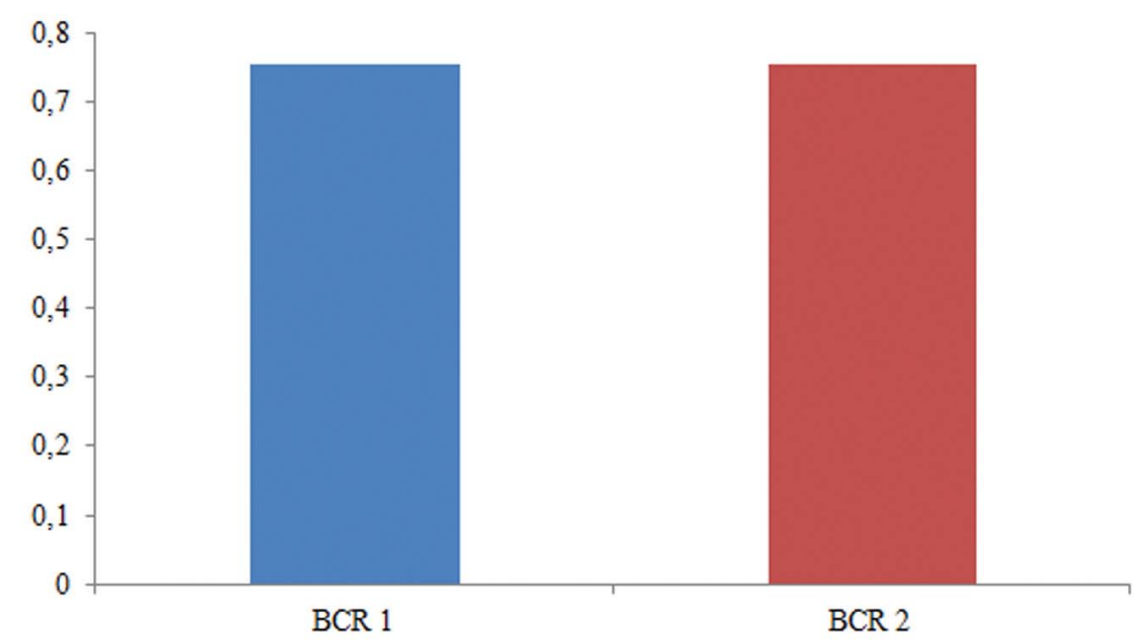

Figure 20. Income-cost indicators of the project

\section{Evaluation of Scenario 2}

The summary of the analysis of Scenario 2 can be seen on the carbon orientation matrix, which shows us the processes during the evaluated time frame - in this case, until 2040 - that we can perceive in the sector, after the project was realised. The project's standing is shown by the blue bubble (Figure 21), its basis being our investment's payoff happening or not somewhere along the line, and if this causes a decrease in emission, or an excess within the sector. As prior analyses also showed us, the project shows good results in both perspectives, since we were able to produce an effective emission decrease value with a payoff for around 2043 with it. 


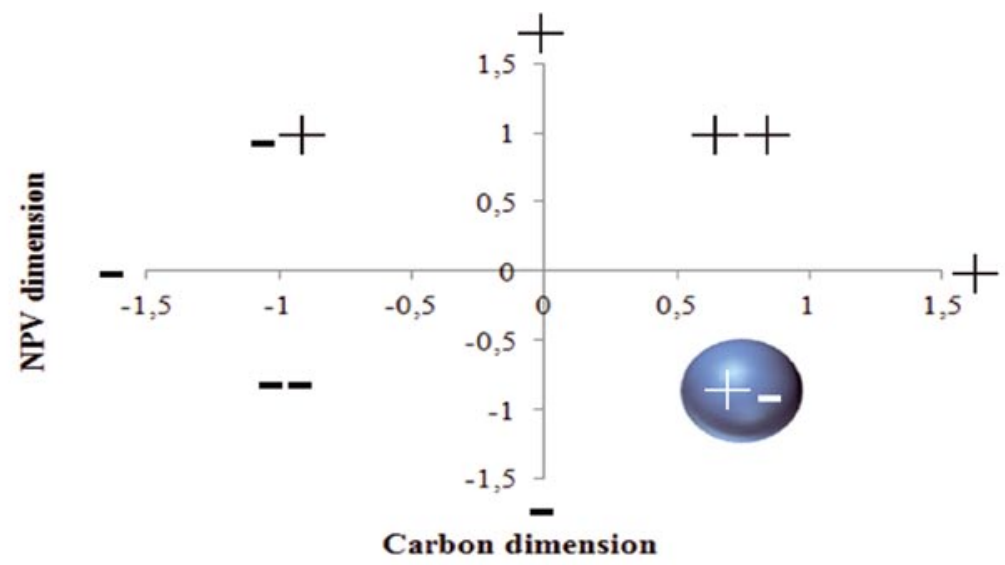

Figure 21. Carbon orientation matrix of Scenario 2

Explanation:

- + : The case when we actualise a project that only increases our emission, and our investment never pays off.

$++:$ The case when the project may show out invested costs to have payoff tendencies, but the activity itself wasn't appropriate to decrease GHG emission.

- - : The case when only high - and non-payoff - costs are required to decrease emission rates.

+ - : Acceptable scenarios, which we can use to generate a $\mathrm{CO}_{2}$ equivalent emission decrease if we allow our investments to pay off in a while. (Even investments paying off after their life cycle, which may have changing externality contents based on political preferences.)

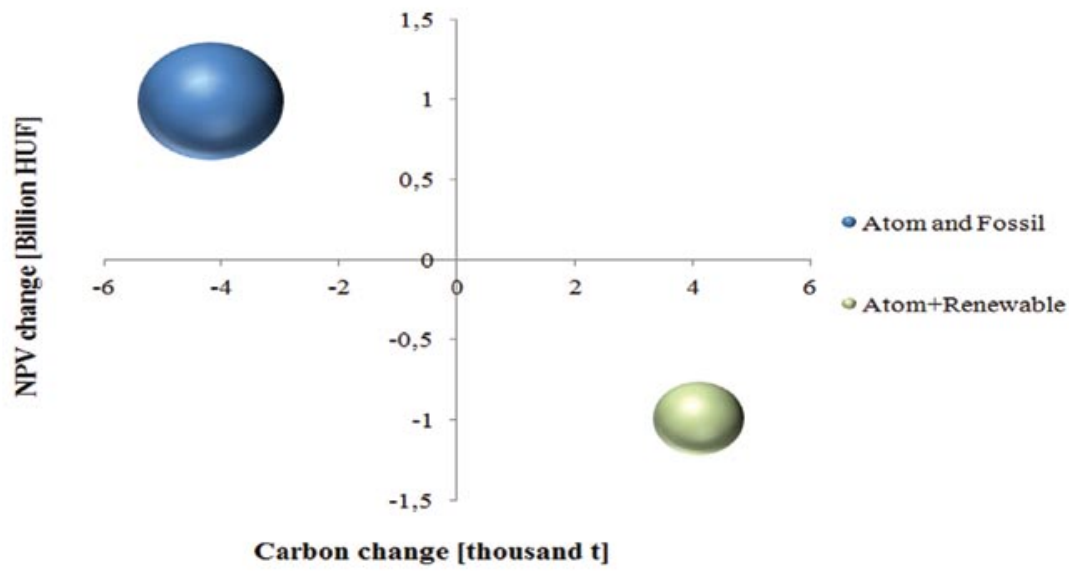

Figure 22. Relative carbon costs

\section{CONCLUSION}

As we've already mentioned during the analysis, determining the difference between the projects is the easiest in this climate policy sector. Our carbon orientation matrixes up until now basically only served the purpose of showing the trends of various projects, however, we made the so-called "relative carbon costs" Figure (Figure 22) to compare those two, where the two scenarios can be compared to each other. The logic of their placement basically didn't change, 
but in this Figure, the size of bubbles becomes more important, which describes the resource intensity of the project, meaning what cost 1 tonnes of $\mathrm{CO}_{2}$ equivalent savings will mean in the 2020-2030 period (if the carbon emission change is negative) / excess emission (if the carbon emission is positive).

In our case, we can see a scenario, in which we wished to supplement increased consumption with nuclear energy, while keeping the coal production. The analyses made it obvious for us, that this approach doesn't only cause a further increase in emission, but the payoff of investments also doesn't happen. This is how when comparing the two different Scenarios, the one which exchanges coal-based energy production with green energy resources is obviously the more advantageous one. Though the resource intensity is higher, we can calculate with much better GHG emission decrease and financial payoff indicators.

\section{REFERENCES}

[1] Acaravci A.,Ozturk I. On the relationship between energy consumption, $\mathrm{CO}_{2}$ emissions and economic growth in Europe. Elsevier, Energy, Volume 35 (2010), Issue 12, December 2010. pp. 5412-5420, DOI: 10.1016/j.energy.2010.07.009

[2] IEA. Key World Energy Statistics. International Energy Agency, 2015, Paris

[3] IEA. World Energy Investment Outlook, Special Report. International Energy Agency, 2014, Paris

[4] Eurostat. Energy balance sheets, 2013 data. Eurostat statistical books, 2015 edition. Publication Office of the European Union, Luxembourg. DOI: 10.2785/388553

[5] Moreno B., López A., Álvarez M. The electricity prices in the European Union. The role of renewable energies and regulatory electric market reforms. Elsevier, Energy, Volume 48 (2012), Issue 1, pp. 307-313 DOI:10.1016/j.energy.2012.06.059

[6] NDA. Magyarország Megújuló Energia Hasznosítási Cselekvési Terve 2010-2020. Nemzeti Fejlesztési Minisztérium, Budapest, 2011

[7] Payne J.E., TaYlor J.P. Nuclear Energy Consumption and Economic Growthinthe U.S.: An Empirical Note. Energy Sources, Part B: Economics, Planning, and Policy, Volume 5 (2010), Issue 3, pp. 301-307. DOI: 10.1080/1556724080253395

[8] Birol F., Argiri M. World energy prospects to 2020. Elsevier, Energy, Volume 24 (1999), Issue 11, November 1999. pp. 905-918, DOI:10.1016/S0360-5442(99)00045-6

[9] JewELL J. Ready for nuclear energy?: An assessment of capacities and motivations for launching new national nuclear power programs. Elsevier, Energy Policy, Volume 39 (2011), Issue 3, pp. 1041-1055. DOI: 10.1016/j.enpol.2010.10.041

[10] NDA. Nemzeti Energiastratégia 2030. Nemzeti Fejlesztési Minisztérium, Budapest, 2012

[11] Lind R. C. Intergenerational equity, discounting, and the role of cost-benefit analysis in evaluation global climate policy. Elsevier, Energy Policy, Volume 23 (1995), Issues 4-5, pp. 379-389. DOI: 10.1016/0301-4215(95)90162-Z

[12] Pigou, A.C. The Economics of Welfare, MacMillan, 1920 Part II., London

[13] Gohar L.K., Shine K.P. Equivalent $\mathrm{CO}_{2}$ and its use in understanding the climate effects of increased greenhouse gas concentrations. Weather, Volumes 62 (2007), pp. 307-311. DOI: 10.1002/wea.103

[14] Bardford M. B., SAlling K. B., Leleur S. Composite decision support by combining cost-benefit and multi-criteria decision analysis. Decision Support Systems, Volume 51 (2011), Issue 1, April 2011, pp. 167-175. DOI: 10.1016/j.dss.2010.12.005

[15] Fogarassy, Cs., Horvath B., Kovacs A. The cost benefit analysis of low-carbon transportation development opportunities for the 2020-2030 EU programming period. Hungarian Agricultural Engineering, Volume 28 (2015), pp. 25-29. DOI: 10.17676/HAE.2015.28.25

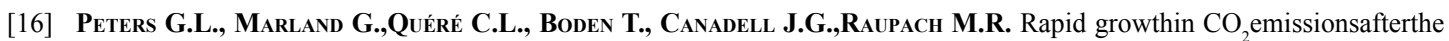
2008-2009 global financial crisis. Nature Climate Change, Volume 2 (2012), pp. 2-4 DOI: 10.1038/nclimate1332

[17] Forsberg C.W. Sustainability by combining nuclear, fossil, and renewable energy sources. Elsevier, Progressin Nuclear Energy, Volume 51 (2009), Issue 1, pp. 192-200. DOI: 10.1016/j.pnucene.2008.04.002

[18] Borocz M., Szoke L., Horvath B. Possible climate friendly innovation ways and technical solutions in the agricultural sector for 2030. Hungarian Agricultural Engineering, Volume 29 (2016), Issue 1. pp. 55-59. DOI: 10.17676/HAE.2016.29.55

[19] Dittmar M. Nuclear energy: Status and future limitations. Elsevier, Energy, Volume (2012) 37, Issue 1, pp. 35-40. DOI: 10.1016/j.energy.2011.05.040

[20] De Groot J.,Steg L., Poortinga W. Values, Perceived Risks and Benefits, and Acceptability of Nuclear Energy. Risk Analysis, Volume 33 (2012), Issue 2. pp. 307-317. DOI: 10.1111/j.1539-6924.2012.01845.X

[21] Fogarassy, Cs. Low-carbon economy. Monográfia. L'Harmattan Publisher, Budapest, 2012, ISBN: 978-963-236-541-1 